\title{
A PERFORMANCE DE UM GRUPO DE PESQUISA EM UMA REDE DO CENTRO-OESTE
}

\author{
Juliana Silva MARTINHO, martinhosjuliana@gmail.com \\ Juliana Cândida Oliveira CUBA, jcocuba@gmail.com \\ Sueli Teresinha de Abreu BERNARDES, abreubernardes@terra.com.br \\ Universidade de Uberaba-UNIUBE \\ Apoio: FAPEMIG/CNPq
}

Recebido em: 15/06/2015 - Aprovado em: 22/11/2015 - Disponibilizado em: 18/12//2015

\begin{abstract}
Resumo
As atividades relatadas neste texto têm como objetivo apresentar a performance de um grupo de pesquisa integrado à Rede de Pesquisadores sobre Professores do Centro-Oeste. Para isso, foi criado um banco de dados por meio de levantamentos, identificação, organização e catalogação da produção bibliográfica, dos projetos desenvolvidos, dos integrantes, das dissertações analisadas, das fichas de análise preenchidas, das dissertações defendidas e dos eventos organizados pela equipe. Por meio de pesquisa bibliográfica, análise documental e buscas em sítios da internet, a coleta de dados abrange o período de 2005-2014.
\end{abstract}

Palavras-chave: Professor. Performance. Grupo de pesquisa. Pesquisa educacional. Análise documental. Banco de Dados.

\section{THE PERFORMANCE OF A RESEARCH GROUP INTEGRATED TOMIDWEST NETWORK}

\begin{abstract}
The activities reported in this text intended to present the performance of a research group integrated to Midwest Teachers Researchers Network (REDECENTRO). For this, a database was created going through surveys, identification, organization and cataloging of bibliographic production, related to the developed projects, members, analyzed and defended dissertations, analysis filled sheets and events organized by the team. Through bibliographical research, document analysis and searches on Internet sites, the data collection covers the period from 2005 to 2014.
\end{abstract}

Key-words: Professor. Performance.Research group.Educational research.Document analysis.Database.

\section{Introdução}

Neste texto, apresentamos as atividades de um projeto de pesquisa desenvolvido no ano de 2014. Nosso objetivo geral foi descrever a performance de um grupo de pesquisa integrado à Rede de Pesquisadores sobre Professores do CentroOeste - REDECENTRO. Para alcança-lo propomos a criação de um banco de dados que consistiu em coletar, organizar e registrar informações sobre os projetos e relatórios de pesquisa concluídos ou em andamento; a produção bibliográfica da equipe local; as dissertações analisadas; as fichas de análise das produções acadêmicas de um Programa de Pós-graduação em Educação-PPGE; as dissertações defendidas por mestrandos da equipe; os membros dos diversos projetos e os eventos organizados. Assim, a construção do Banco de Dados foi objetivo e, posteriormente, fonte para os resultados apresentados neste texto. 
As atividades aqui comentadas constituem um subprojeto da pesquisa "Estudos acadêmicos sobre professores no Centro-Oeste", integrado à REDECENTRO.Essa Rede tem como objetivo básico estudar as teses e dissertações que se referem ao professor, desenvolvidas nos programas de pós-graduação em educação das instituições conveniadas. De modo colaborativo e integrado, essa investigação apresenta um caráter interdisciplinar ao agregar diversos pesquisadores de diferentes áreas os quais investigam a formação, a profissionalização e a prática docente. Dessa Rede fazem parte sete universidades: UFG, UnB, UFMS, UFMT, UFT, UFU e UNIUBE.

Em 2011, a REDECENTRO associouse ao Observatório Internacional de laProfissión Docente, da Universidade de Barcelona,Espanha, dirigido pelo Prof. Francisco Imbernón, alcançando, desse modo, umaamplitude internacional.

A equipe do Programa a que este estudo se refere, é formada por professores do Programa de Pós-graduação em Educação da instituição e de um Instituto Federal de Educação, Ciências e Tecnologia, além de egressos, professores e alunos da graduação, uma professora da educação básica e colaboradores. Assim, seu caráter integrativo efetiva-se nas dimensões horizontal e vertical.

Nosso entendimento sobre o banco de dados apoia-se no conceito de ser um conjunto de elementos integrados entre si, que se relacionam de forma lógica, consolidando registros armazenados de forma separada em arquivos. Com o desenvolvimento dos procedimentos de pesquisa e com a socialização do conhecimento por meio da internet, a utilização de bancos de dados na coleta de informações e em sistemas de apoio às pesquisas em educação tem-se mostrado um instrumento eficaz no gerenciamento do crescente volume de informações. Junto ao grau de evolução tecnológica em que se depara a informática atualmente, um banco de dados torna-se uma ferramenta ágil e garantida.

Segundo Mello (1999, apud MATSUMOTO, 2006, p. 48)

\begin{abstract}
Um registro de banco de dados é uma unidade de informações sobre algo. O banco de dados ideal fornece acesso rápido aos dados. Um bom sistema de banco de dados também conserva a integridade, promove a independência, evita a redundância, garante a segurança e fornece procedimentos para manutenção dos dados.
\end{abstract}

Pensamos, ainda, que o primeiro passo para a efetivação de uma análise de dados é sua organização. Quando recebemos um conjunto de dados originários de documentos, de informantes, de material bibliográfico, de sítios da internet ou de outras fontes depesquisa, normalmente eles nos chegam na melhor configuração possível, mas para as pessoas que trabalhavam com eles antes, e essa dificilmente é a melhor forma para os investigadores. Por isso, é de extrema importância que gastemos algum tempo na organização dos dados. 
Consideramos que os grupos de pesquisa, institucionalizados no Brasil através do $\mathrm{CNPq}$, constituem uma prática que tem consolidado a investigação científica no país. Esses grupos são responsáveis por grande parte das investigações realizadas na atualidade e também pela formação de inúmeros pesquisadores. Yázigi (2005) destaca que a capacidade de o pesquisador apresentar criatividade é basilar para o avanço do conhecimento científico, e os grupos de pesquisa podem contribuir para que os futuros profissionais desenvolvam a habilidade da criatividade, permitindo a reflexão e o questionamento de temas que emergem de seu contexto social e científico. As equipes de investigação podem contribuir para que outros olhares sejam efetuados e que novas ideias possam surgir. Além disso, os grupos têm papel formador nos requisitos de rigor e a qualidade na pesquisa científica.

\section{A origem do grupo de pesquisa}

Em 1998 foi criado uminstituto de formação de educadores, na universidade pesquisada,com a finalidade de aglutinar cursos, programas e pesquisas voltadospara a formação do educador. A equipe do IFE propôs, como objetivo inicial, prestar apoio pedagógico aos docentes e assistentespedagógicas dos diversos cursos de graduação. Foi criado, então, em dezembro de 1999, o embrião de um "Grupo de Apoio Pedagógico", com o intento de promover reflexões erevelar práticas significativas parao fazer educativo. Ao ser implantado, seus integrantes, instigados pelos princípios de integração pesquisa, ensino e extensão do instituto, e pela própria reflexão do trabalho realizado, propuseramuma pesquisa sobre o apoio pedagógico oferecido aos professores.Assim foi criado o Grupo de Apoio Pedagógico e Pesquisa que se propôs alcançar três objetivos: investigar se as ações pedagógicas desenvolvidas e outras em andamento com os professores da instituição contribuíam para mudanças na prática docente; identificar anatureza dessas mudanças; e, por último, analisar a produção teórica sobre a formação do professor. Privilegiando a busca decompreensão do comportamento docente a partir dos sujeitos da investigação, foram definidasestratégias representativas de pesquisa de campo. Os resultados eram discutidos entre os pesquisadores e os professores envolvidos no espaço formativo de um curso de especialização sobre a docência universitária, também desenvolvido pela equipe. Assim, foram desenvolvidos três projetos de pesquisa colaborativa e de reflexão sobre a prática pedagógica (ABREU-BERNARDES et al, 2001).

Em 2005 a equipe do GAPP foi convidada a fazer parte de um grupo interinstitucional de pesquisa sobre a produção acadêmica com foco no professor, composto por pesquisadores de programas de 
pós-graduação em educação da Região Centro-Oeste e coordenado por professores da Universidade Federal de Goiás. Esse grupo evoluiu para a criação da Rede de Pesquisadores sobre Professores do CentroOeste, a REDECENTRO.

\section{A trajetória investigativa}

Para analisar a performance desse grupo, a partir da integração à REDECENTRO, neste estudo inicialmente realizamos o levantamento do corpusa ser pesquisado. Optamos, então, por uma tipologia que se concretiza em uma pesquisa documental, com aporte em Lüdke e André (1986). Consideramos o material arrolado como fonte primária, pois se trata de documentos que analisamos tal como foram concebidos por seus autores. Esse material insere-se no contexto sócio histórico da pesquisa, e, assim como qualquer documento, detêm um conteúdo passível de análise. No entanto, o discurso destes documentos não foi enfocado nesta pesquisa, o que deverá ser feito em investigações posteriores.Nosso trabalho não tem, portanto, uma perspectiva sócio discursiva. O alcance do estudo é a quantificação, organização e registro do material arrolado relativo ao período 20052014.

$\mathrm{Na}$ busca para alcançar nossos objetivos, realizamos um processo metodológico que abrangeu, além da pesquisa documental citada, a pesquisa bibliográfica e em sítios da internet, atividades de estudo em grupo, participação em eventos e observações. As fontes abrangeram: currículos na Plataforma Lattes; banco de dissertações da Biblioteca Central da UNIUBE, página do Mestrado em Educação no portal da UNIUBE; arquivo da pesquisa; fichas de análise das dissertações, projetos de pesquisa concluídos e em andamento.

Concretizamos nossa proposta em doze etapas metodológicas: i. realizamos a leitura e a discussão do projeto de pesquisa a que o subprojeto de iniciação científica se integra;ii. definimos o corpus da pesquisa;iii. identificamos os membros da equipe, período 2005-2014, o qual abrangeu o início das atividades do grupo até a data de realização desta pesquisa;iv. arrolamos os projetos de pesquisa concluídos e em andamento; v. identificamos os planos de trabalho e os relatórios de iniciação científica; vi. realizamos a leitura dos currículos dos participantes na Plataforma Lattes para identificação da produção bibliográfica;viii. listamos as dissertações do PPGE analisadas pelo grupo de pesquisa local;ix. elencamos as dissertações defendidas, as quais se integraram à REDECENTRO; $\mathrm{x}$. relacionamos as fichas de análise das dissertações; xi. inventariamos os eventos científicos organizados pela equipe local;xii. tabulamos os dados, utilizando recursos do Word e do Excel; xiii. analisamos os resultados. 
Essas atividades foram realizadas em paralelo a estudos teóricos, discussões no grupo de pesquisa, participação em eventos em que se discutiam temáticas relacionadas à pesquisa em educação e elaboração de trabalhos para socialização em encontros e seminários.

\section{Resultados da pesquisa}

A partir dos levantamentos feitos, elencamos os dados resumidos a seguir.

Tabela 1 - Definição do corpus da pesquisa para criação do banco de dados.

\begin{tabular}{|c|c|c|}
\hline \multicolumn{2}{|c|}{ Corpus da pesquisa } & $\mathbf{n}^{\mathbf{0}}$ \\
\hline \multicolumn{2}{|c|}{ Membros do grupo } & 37 \\
\hline \multicolumn{2}{|c|}{ Projetos de pesquisa desenvolvidos } & 03 \\
\hline \multicolumn{2}{|c|}{ Dissertações com foco no professor } & 58 \\
\hline \multicolumn{2}{|c|}{ Currículos Lattes dos participantes } & 37 \\
\hline \multicolumn{2}{|c|}{ Fichas de análise } & 58 \\
\hline \multicolumn{2}{|c|}{ Dissertações defendidas } & 07 \\
\hline \multicolumn{2}{|c|}{ Eventos científicos organizados } & 14 \\
\hline \multicolumn{3}{|c|}{ Eventos artísticos } \\
\hline \multirow{4}{*}{$\begin{array}{l}\text { Produção } \\
\text { bibliográfica }\end{array}$} & artigos & 14 \\
\hline & capítulos de livros & 13 \\
\hline & trabalhos completos & 38 \\
\hline & resumos & 42 \\
\hline
\end{tabular}

Fonte: arquivo da pesquisa, UNIUBE/REDECENTRO.

Em relação aos membros, dos 37 (trinta e sete) participantes durante todo o processo, 7 (sete) eram mestrandos e 4 (quatro) mestres. Entre os 8 (oito) pesquisadores que possuem doutorado, 3(três) são professores tanto do mestrado como da graduação, e uma é professora da educação básica. Participam ou participaram também 14 (quatorze) alunos bolsistas de iniciação científica. Para essa pesquisa em rede, o projeto contou, igualmente, com dois profissionais como apoio técnico. Houve várias mudanças na composição do grupo e da equipe inicial apenas três permanecem.

Esse grupo desenvolveu três projetos de pesquisa (tabela 2) que têm agregado orientações tanto de mestrado como de iniciação científica. Além desses, um quarto projeto foi submetido neste semestre, tendo como objeto os estudos acadêmicos sobre o professor no Centro-Oeste, período 2010-2014.

Tabela 2 - Projetos de pesquisa desenvolvidos, produções e orientação.

\begin{tabular}{|c|c|c|c|c|c|}
\hline $\begin{array}{c}\text { Projetos de } \\
\text { Pesquisa }\end{array}$ & $\begin{array}{l}\mathrm{N}^{\mathrm{o}} \text { de } \\
\text { partici- } \\
\text { pantes }\end{array}$ & $\begin{array}{c}\mathrm{N}^{\circ} \mathrm{de} \\
\text { produç } \\
\text { ôes }\end{array}$ & $\begin{array}{c}\mathrm{N}^{\mathrm{o}} \mathrm{de} \\
\text { orientaç } \\
\text { ões }\end{array}$ & Situa-ção & $\begin{array}{c}\text { Financia } \\
\text { mento }\end{array}$ \\
\hline $\begin{array}{c}\text { Estudos } \\
\text { acadêmicos } \\
\text { sobre o } \\
\text { professor no } \\
\text { Centro- } \\
\text { Oeste } \\
(2006-2009) \\
\end{array}$ & 15 & 10 & 02 & $\begin{array}{c}\text { Em } \\
\text { andament } \\
\text { o 2014- }\end{array}$ & $\begin{array}{c}\text { FAPEM } \\
\text { IG } \\
\text { /PAPE }\end{array}$ \\
\hline $\begin{array}{c}\text { Tipos e } \\
\text { procediment } \\
\text { os de } \\
\text { pesquisa } \\
\text { sobre o } \\
\text { professor na } \\
\text { Região } \\
\text { Centro- } \\
\text { Oeste } \\
\end{array}$ & 13 & 21 & 07 & $\begin{array}{c}\text { Concluíd } \\
\text { o } 2011 \text { - } \\
2013\end{array}$ & $\begin{array}{c}\text { FAPEM } \\
\text { IG/ } \\
\text { PAPE }\end{array}$ \\
\hline $\begin{array}{c}\text { A produção } \\
\text { acadêmica } \\
\text { sobre } \\
\text { professores: } \\
\text { estudo } \\
\text { interinstituc } \\
\text { ional da } \\
\text { Região } \\
\text { Centro- } \\
\text { Oeste - } \\
\text { subprojeto } \\
\text { da UNIUBE }\end{array}$ & 17 & 74 & 02 & $\begin{array}{c}\text { Concluíd } \\
\text { o, } 2006- \\
2011\end{array}$ & $\begin{array}{c}\text { FAPEM } \\
\text { IG/ } \\
\text { PAPE }\end{array}$ \\
\hline
\end{tabular}

Fonte: Currículos na Plataforma Lattes - CNPq dos participantes e arquivo da pesquisa.

A maior extensão temporal do projeto “A produção acadêmica sobre professores: estudo interinstitucional da Região Centro- 
Oeste-subprojeto da Universidade de Uberaba" (2006) deve-se ao fato de ter sido solicitada prorrogação.Pelos dados, é possível perceber que o total de produções é crescente. O primeiro projeto desenvolvido teve uma média de 11 produções por ano; o segundo, 10, e o que está em andamento deu origem a 10 trabalhos. Observamos, também,que o número de trabalhos completos vem decrescendo, e isso pode ser decorrente do maior envolvimento com a elaboração de dissertações, capítulos de livros e artigos. Por outro, lado, a socialização e a troca de experiências que a participação em eventos possibilita, ficam prejudicadas.

Em relação ao número de participantes, os dados da tabela 2 apenas informam quantos membros se envolveram, em algum momento com o desenvolvimento do projeto. Não significa que seja a realidade atual. Segundo a atual coordenadora, neste primeiro semestre de 2015 há apenas cinco pesquisadores, incluindo as alunas do PIBIC, realizando as atividades.

Sobre a produção bibliográfica, apresentamos mais dados (tabela 3), os quais nos permitem aprofundar o conhecimento sobre o que a equipe criou em sua existência

No período em foco, identificamos 109 produções, segundo os currículos dos integrantes da UNIUBE/REDECENTRO registrados na Plataforma Lattes.
Tabela 3 - Produção bibliográfica da equipe de pesquisa 2005-2014.

\begin{tabular}{lllcccc}
\hline ano & artigo & $\begin{array}{c}\text { capítulo } \\
\text { de livro }\end{array}$ & $\begin{array}{c}\text { Traba } \\
\text { lho } \\
\text { completo }\end{array}$ & \multicolumn{2}{c}{$\begin{array}{c}\text { resumo } \\
\text { técnico }\end{array}$} & $\begin{array}{c}\text { expan-Subtotal } \\
\text { dido }\end{array}$ \\
2005 & - & - & 02 & 01 & - & 03 \\
2006 & - & - & 06 & 01 & - & 07 \\
2007 & - & - & 03 & 01 & - & 04 \\
2008 & - & 01 & - & 03 & - & 04 \\
2009 & 01 & 03 & 06 & 06 & - & 16 \\
2010 & 03 & 02 & 07 & 03 & - & 15 \\
2011 & 02 & 03 & 04 & 11 & 07 & 27 \\
2012 & 04 & 01 & 01 & 01 & 03 & 10 \\
2013 & 01 & - & 07 & 02 & 01 & 11 \\
2014 & 02 & 03 & 02 & 03 & - & 10 \\
\hline total & $\mathbf{1 4}$ & $\mathbf{1 3}$ & $\mathbf{3 8}$ & $\mathbf{3 2}$ & $\mathbf{1 2}$ & $\mathbf{1 0 9}$ \\
\hline
\end{tabular}

Fonte: Plataforma Lattes - CNPq, 2014.

Nos textos referentes ao período em estudo, encontramos, de modo predominante, os resumos e trabalhos completos apresentados em sessões de comunicações orais ou em sessões de pôsteres em eventos. Ressaltamos que dessas comunicações, quatro foram apresentadas em congressos em Portugal e dois na Espanha. Observamos que a maioria dos trabalhos não foi transformada em artigos, o que poderia ampliar a socialização do conhecimento construído. Outro aspecto é que a maioria das produções (77\%) foi elaborada em coautoria, o que expressa um trabalho colaborativo. Dos treze capítulos elaborados, três foram publicados em livros organizados pela própria equipe da REDECENTRO, nos quais são relatadas as investigações realizadas em cada universidade conveniada. 
Integrados à proposta de pesquisa da REDECENTRO, seis alunos do Curso de Mestrado em Educação desenvolveram seis dissertações (quadro 1), todos sob a orientação da Profa. Sueli Teresinha de AbreuBernardes.

Quadro 1 - Dissertações do Mestrado integradas à REDECENTRO, UNIUBE, 2009-2014.

\begin{tabular}{|c|c|c|}
\hline Autor & Título da dissertação & Ano \\
\hline $\begin{array}{l}\text { Elton Ant } \\
\text { Alves Pe }\end{array}$ & $\begin{array}{l}\text { A produção acadêmica sobre a } \\
\text { Educação Básica no Curso de } \\
\text { Mestrado em Educação da } \\
\text { UNIUBE: tipos, procedimentos } \\
\text { de pesquisa e referencial teórico } \\
\text { de } 2003 \text { a } 2012\end{array}$ & 201 \\
\hline $\begin{array}{c}\text { Eder Teixeira } \\
\text { Piau }\end{array}$ & $\begin{array}{l}\text { Professores e/ou graduados de } \\
\text { Educação Física? Um estudo na } \\
\text { mesorregião do Triângulo } \\
\text { Mineiro e Alto Paranaíba }\end{array}$ & 2012 \\
\hline $\begin{array}{c}\text { Marilene Dias } \\
\text { de Menezes } \\
\text { Campos }\end{array}$ & $\begin{array}{l}\text { Concepções de formação inicial } \\
\text { de professores um estudo a partir } \\
\text { das produções acadêmicas do } \\
\text { centro-oeste, período } 1999-2005\end{array}$ & 2012 \\
\hline $\begin{array}{c}\text { oamarZanolini } \\
\text { Nazareth }\end{array}$ & $\begin{array}{c}\text { Movimentos construtivos para o } \\
\text { ser professor universitário um } \\
\text { estudo do conhecimento sobre } \\
\text { processos institucionais }\end{array}$ & 2011 \\
\hline $\begin{array}{r}\text { Edu } \\
\text { Car } \\
\text { Azar }\end{array}$ & $\begin{array}{r}\text { Ser e fazer- } \\
\text { desvendando a } \\
\text { professor c }\end{array}$ & 2011 \\
\hline $\begin{array}{l}\text { Rudney } \\
\text { Ferreira } \\
\text { Bonfim }\end{array}$ & $\begin{array}{l}\text { Mulheres de ouro experiências } \\
\text { vividas por esposas de } \\
\text { garimpeiros que se tornaram } \\
\text { professoras em Itaituba-PA }\end{array}$ & 2009 \\
\hline $\begin{array}{l}\text { Raimundo } \\
\text { Márcio Mota } \\
\text { de Castro }\end{array}$ & $\begin{array}{l}\text { Tocar em frente asensinhanças da } \\
\text { dúvida: a busca da identidade do } \\
\text { ensino religioso }\end{array}$ & 2009 \\
\hline
\end{tabular}

Fonte: Banco de Dissertações, Biblioteca Central, UNIUBE.

A atuação junto à graduação é grande, como é possível observar nos dados do quadro 2, o que possibilita a formação de jovens pesquisadores. Uma informação relevante diz respeito à formação da própria equipe. Desde os primeiros passos do grupo, seus integrantes continuarem sua formação.
Assim, 14 (quatorze) fizeram o mestrado, e 5 (cinco), o doutorado em educação.

O número de alunos de iniciação científica é representativo. Do projeto: “A produção acadêmica sobre professores: estudo interinstitucional da Região Centro-Oestesubprojeto da UNIUBE” foram desenvolvidos os seguintes planos de trabalho: "A construção da prática pedagógica no TelEduc”, Norberto A. Pereira (2006); “A pesquisa em rede como poiésis", Marcelo G. da Silva (2006); "Fazendo história: a abordagem histórica na pesquisa a respeito da formação docente", Raniele D. Oliveira (2007); "A produção docente em rede", Polliana Estevam (2007); "Do uno ao diverso: representações e práticas culturais na formação de professore", Polyana G. Lopes(2008); “A pesquisa como poiésis: análise da dimensão artística na prática docente em dissertações do curso de Mestrado em Educação da UNIUBE”, Andréia C. Miranda (2008); “A formação de professores no uso de tecnologias na Educação", Cristiane S. Lopes (2008); "Escolha do tema e subtemas nas produções acadêmicas sobre o professor da educação básica no Programa de Mestrado em Educação da UNIUBE”, Maria A. Gama (2010); “A educação inclusiva e sua problematização na formação de professores nas produções do programa de mestrado em educação da UNIUBE”, Elen Clar F. Silva (2010). Os planos de trabalho supracitados foram financiados pelo Programa de Apoio à 
Pesquisa - PAPE. Foram também concluídos três planos de trabalho, vinculados ao mesmo projeto de pesquisa: "A escolha do tema e subtemas nas produções acadêmicas sobre o professor da educação básica no Programa de Pós-graduação em Educação da UNIUBE. 2001-2009”, Gisele N.O. Costa (2009-2010) e ElenClar F. Silva (2010). Em 2011 a continuidade deste plano foi realizada por Deborah Evelyn Cunha (2011).

$\mathrm{O}$ segundo projeto "Tipos e procedimentos de pesquisa sobre o professor na Região Centro-Oeste" foi desenvolvido com o plano de trabalho: "O ser professor na literatura produzida nos programas de pósgraduação em educação da Região CentroOeste", Leonora de Abreu Bernardes (2012) e Bruna Piau Reis (2012-2013).

O projeto de pesquisa em andamento é "Estudos acadêmicos sobre o professor no Centro-Oeste (2006-2009)" desenvolve-se com dois planos de trabalho: "Estado da arte das pesquisas acadêmicas sobre o professor no Centro-Oeste, 2006-2009”, Bruna P.Reis (2013-2015) e "Banco de dados institucional da Rede de Pesquisadores sobre Professores do Centro-Oeste - 2006-2009" e Juliana Silva Martinho (2014). Todos os 16 alunos receberam bolsa do Programa de Apoio à Pesquisa-PAPE/UNIUBE e/ou FAPEMIG.

As produções acadêmicas são analisadas por de uma ficha elaborada pela equipe da REDECENTRO. Ao ler a tese ou a dissertação, o leitor registra os dados de identificação: autor, título, ano de defesa, linha de pesquisa e palavras-chave. Em seguida, identifica o tema — se formação, profissionalização ou prática docente, apresentando seu referencial teórico. Outros indicadores de análise são: as questões, o problema, a abordagem, a modalidade, o método, os tipos e procedimentos de pesquisa e o ideário pedagógico explicitado. Finalmente, são analisados os resultados e as conclusões. Após as análises locais, os resultados são discutidos em seminários regionais realizados alternadamente nas universidades parceiras do Centro-Oeste. Em um terceiro momento, cada instituição analisa uma temática abrangendo todas as fichas de análise da região. $\mathrm{Na}$ instituição investigada, a temática atual são os tipos e procedimentos de pesquisa e seu referencial teórico, mas, no primeiro projeto, o foco proposto foi o tema de investigação escolhido.

Das fichas que se encontram no arquivo do curso de Mestrado em Educação pesquisado, procuramos elencar o número de fichas foram analisadas em cada ano. De um total de 179 dissertações defendidas de 2003 a 2014, 58 foram selecionas pelos integrantes da equipe,a partir da análise do foco sobre o professor. Dessas leituras, o maior percentual verifica-se no ano de 2006 com um total de 24 leituras que representam mais de quarenta e um por cento das dissertações lidas (tabela 4). 
Tabela 4 - Fichas de análise preenchidas pelos integrantes da UNIUBE/REDECENTRO (2005-2014).

\begin{tabular}{c|c}
\hline Ano & Produção \\
\hline 2014 & 01 \\
\hline 2013 & 04 \\
\hline 2012 & 14 \\
\hline 2011 & 01 \\
\hline 2010 & 00 \\
\hline 2009 & 00 \\
\hline 2008 & 08 \\
\hline 2007 & 04 \\
\hline 2006 & 24 \\
\hline 2005 & 02 \\
\hline Total & $\mathbf{5 8}$ \\
\hline
\end{tabular}

Fonte: Arquivo do grupo de pesquisa, 2014.

Segundo dados identificados, as fichas são preenchidas por pares, sendo necessário que o aluno de iniciação científica ou o aluno de mestrado seja acompanhado na leitura por um pesquisador doutor.

Faz parte da metodologia de trabalho da Rede a realização de seminários locais, no âmbito de cada Programa, para discutir as análises realizadas, a metodologia e 0 referencial teórico. Semestralmente, também são realizados seminários regionais nas instituições conveniadas, para discutir o andamento da pesquisa. Nesses últimos participam pesquisadores de todas as instituições conveniadas na REDECENTRO. No entanto, a prática de seminários locais tem diminuído na universidade analisada,conforme observado nas respectivas listas de presença, possivelmente em decorrência da redução do tempo dos integrantes para realizar os estudos, o que deixa maior responsabilidade aos seminários regionais, sob pena de comprometer o rigor da investigação.

Observamos que a ficha sofreu mudanças durante o processo e, segundo registros de memoriais dos seminários, isso ocorreu em decorrência da avaliação do instrumento realizada de modo contínuo e, sobretudo, a partir de avaliações e discussões nas reuniões técnicas dos coordenadores das equipes e nos seminários regionais.

Para aprofundar os estudos teóricos e trocar experiências com alunos e professores da pós-graduação da UNIUBE e de instituições congêneres da região, o grupo promove eventos científicos, os quais elencamos no quadro 3.

Para aprofundar os estudos teóricos e trocar experiências com alunos e professores da pós-graduação da UNIUBE e de instituições congêneres da região, o grupo promove eventos científicos, os quais elencamos a seguir: XXII Seminário da Pesquisa A produção acadêmica sobre professores: estudo interinstitucional da Região Centro-Oeste; IV Encontro da REDECENTRO; XIV Encontro dos Estudantes de Iniciação Científica PIBIC (2014); Mesa-redonda Filosofia e educação: A linguagem em Santo Agostinho e Jurgen Habermas (2013); Seminário sobre Direitos Autorais (2013); Palestra A exclusão social, o insucesso e o abandono escolar: uma análise da sociedade contemporânea portuguesa (2013); Minicurso: Construção e socialização do conhecimento científico (2013); Minicurso: A pesquisa documental no processo investigativo em educação (2013); Minicurso: A triangulação 
metodológica na pesquisa (2013); Seminário: As ideias que predominaram no pensamento ocidental (2012).

Dois aspectos nos chamaram a atenção: primeiro a maior ocorrência desses eventos de extensão no ano de 2013. Outro e a organização de três seminários regionais, nos quais participam os pesquisadores das instituições conveniadas à REDECENTRO, com a média de duração de três dias.

Entendendo que a ciência e a arte realizam diálogos possíveis, a equipe da pesquisada organizou várias mostras, expondo obras de artistas e artesões da cidade. Assim, foram realizados: a) Mostra de artesanato, 2014; b) Arte em fogo - mostra de cerâmica, 2013; c)Mostra de pintura: Paisagens do Centro-Oeste, 2012;b) Mostra de esculturas, 2010; Sol e Terra: cerâmica 2010;Sentidos: arte em cerâmica,vários artistas, 2009; Faces da religiosidade mineira, 2008; Arte e Objetos, 2008; Diversidades: cerâmicas, 2007; Pássaros de voo breve com desejos de infinito: esculturas, 2007; Arte em barro e ferro, 2006; Sertões dos Confins: instalações, 2006.Essas mostras são realizadas simultaneamente aos eventos científicos. $\mathrm{Na}$ figura 6, apresentamos um recorte de uma dessas mostras artísticas.

\section{Considerações finais}

A organização e o uso de documentos e dados em pesquisa deve ser apreciado e recomendado devido a riqueza de informações e análises que deles podem ser extraídos. Pensamos que, a partir de sua consulta, será possível encontrar um maior aproveitamento e agilidadenas investigações, além possibilitar uma reflexão sobre o que foi realizado. Os dados quantitativos $\mathrm{e}$ as informações apresentadas constituem indicadores da performance do grupo, mas não são suficientes para conclusões sobre a qualidade e o rigor. Esses aspectos merecem a realização de um segundo momento investigativo com uma possível leitura hermenêutica da produção bibliográfica, dos projetos, fichas de análise e das dissertações construídas.

\section{Referências}

ABREU-BERNARDES, S. T. et al. Grupo de Apoio Pedagógico e Pesquisa: educadores em travessia. In: REUNIÃO ANUAL DA ANPED, 24, 2001, Caxambu. Anais... Caxambu: ANPED, 2001. 1 CD-ROM.

MATSUMOTO, C. Y. A importância do banco de dados em uma organização.Revista de Ciências Empresariais, v. 3, n.1, p.45-55, jan./jun. 2006.

LÜDKE, M., ANDRÉ, M. E. D. A. Pesquisa em educação: abordagens qualitativas. São Paulo: EPU, 1986.

YÁZIGI, E. Deixe sua estrela brilhar. Criatividade nas ciências humanas e no planejamento. São Paulo: CNPq/Plêiade, 2005. 